Çukurova Üniversitesi Mühendislik Mimarlık Fakültesi Dergisi, 32(2), ss. 85-99, Haziran 2017

Çukurova University Journal of the Faculty of Engineering and Architecture, 32(2), pp. 85-99, June 2017

\title{
Kızıldere-Güveloğlu (Ceyhan-Adana) Civarının Tektono-Stratigrafisi
}

\author{
Ulvi Can ÜNLÜGENÇ ${ }^{* 1}$, Ahmet Can AKINCI ${ }^{1}$ \\ ${ }^{1}$ Çukurova Üniversitesi, Mühendislik Mimarlık Fakültesi, Jeoloji Mühendisliği Bölümü, Adana
}

Geliş tarihi:20.03.2017

Kabul tarihi:20.04.2017

$\ddot{\mathbf{O z}}$

Güneydoğu Anadolu ve Doğu Akdeniz Havzalarını (Adana Baseni, İskenderun Baseni) sınırlayan kenet kuşağı, Misis, Andırın ve Engizek hattı boyunca tektonik bir yükselim şekliyle uzanmaktadır. Bu yükselim alanı Adana'nın Ceyhan ilçesinin GB'sında yer alan çalışma bölgesinde Misis yapısal yükselimi olarak isimlendirilmektedir. Bu yükselim alanının batısında ise kenet zonu bugün güneybatı Akdeniz'de deniz seviyesi altında kalmış bir sırt boyunca Kuzey Kıbrıs’taki Girne dağ silsilesine kadar uzanmaktadır. Misis Yapısal Yükselimi Adananın doğu-güneydoğusunda bulunan, kuzeydoğu - güneybatı istikametinde uzanan ve yüksekliği 750 metreye ulaşan bir dağ silsilesi olup Adana ve İskenderun havzalarını birbirinden ayırmaktadır. Anadolu, Afrika ve Arap levhalarının üçlü birleşme noktasına (triple junction) oldukça yakın konumda bulunan ve bu levhalar arasındaki jeodinamik hareketlerin etkisi ile şekillenmiş olan Misis Yapısal Yükselimi bölgenin depremselliği ve jeolojik geçmişi açısından önemli bir tektonik uzanım konumundadır. Çalışma sahası olan Kızıldere-Güveloğlu (Yakapınar) bölgesinde Eosen-Oligosen yaşlı Bulgurkaya Formasyonu tektonik dokanak ile Alt-Orta Miyosen yaşlı Karataş Formasyonunu üzerlemektedir. Bu birim üzerine diskordans ile Pliyosen (?) yaşlı yamaç molozu çökelleri gelmektedir. $\mathrm{Bu}$ çökellerin üzerinde ise yine düşük dereceli açısal bir uyumsuzluk ile yataya yakın bir konumda olmak üzere Pliyo-kuvaterner yaşlı traverten ve kaliçi çökelleri gelir. Tüm bu birimler yükselim alanının kuzey ve güney kesiminden Kuvaterner yaşlı alüvyon örtü ile sınırlandırılmıştır.

Anahtar Kelimeler: Adana-Ceyhan, Tektono-stratigrafi, Jeodinamik, Tektonik

\section{Tectono-Stratigraphic Investigation of Kızıldere-Güveloğlu (Ceyhan-Adana) Region}

\begin{abstract}
The suture zone limiting the Southern Anatolian and Eastern Mediterranean basins (e.g. Adana Basin, İskenderun Basin) extends as a tectonic uplift throughout Misis-Andırın-Engizek lineament. This uplifted area is named as Misis Structural High in the investigated area located SW of Ceyhan district of Adana. To the west of this uplifted area, the suture zone extends southwest as far as to the Kyrenean mountain range to the north of Cyprus throughout underwater within the Mediterranean. The Misis Structural High lies as a mountainous range that reaches up to $750 \mathrm{~m}$ high at a NE-SW direction to the E-SE of Adana and separates the Adana and İskenderun basins from each other. Misis Structural High with its close position to the triple junction of the Anatolian, African and Arabian Plates that affecting the geodynamic
\end{abstract}

*Sorumlu yazar (Corresponding author): Ulvi Can ÜNLÜGENÇ, ulvican@cu.edu.tr 
movements of these plates, is one of the key tectonic lineament for understanding the geologic history and the seismicity of the region. The Eocene-Oligocene Bulgurkaya Formation is tectonically overlain the Lower-Middle Miocene Karataş Formation in Kızıldere-Güveloğlu (Yakapınar) region. Pliocene (?) slope debris deposits unconformably overlain this unit. On top of these sediments, Plio-Quaternary travertine and caliche sediments comes with a with low degree angular unconformity. All these units are bounded by Quaternary alluvium bounded the Structurl High area from the northern and southern parts of the region.

Keywords: Adana-Ceyhan, Tectonostratigraphy, Geodynamic, Tectonic

\section{GíRiș}

Çalışma alanı tektonik yönden oldukça aktif bir bölge olup, Afro-Arap levhaları ve Anadolu levhacığının kenet yaptığı bir zona oldukça yakın bir konumda yer almaktadır. Bölgenin tektonik yönden aktif olması, beraberinde sismik aktiviteyi ve depremselliği de getirmektedir. Belirtilen bu levha sınırlarının Güney Tetis okyanusunun Kretase dönemi sonlarında kıta kenarlarına yerleşmiş olan kalıntıları Türkiye'nin güney kesimi üzerinden Bitlis-Zagros hattı boyunca İran'a doğru uzanmaktadır [1,2]. Allokton konumdaki bu güney Tetis kalıntı birimlerinin Türkiye'nin kuzeyinde bulunan tek bir Tetis okyanusundan türediği düşüncesi jeolojik çevrelerce daha az kabul gören bir senaryo olarak karşımıza çıkmaktadır.

Bunun yanı sıra Güney Tetis okyanusunun Geç Kretase-Erken Tersiyer zamanında kuzey yönlü yitimi, doğrultu atımlı tektonik ve çarpışmalı tektonik rejim neticesinde aşamalı olarak kapandığ1 görüşü çalışmacılar tarafından geniş bir kabul görmektedir.

Güneydoğu Türkiye ile Doğu Akdeniz Basenlerini (örneğin Adana Baseni, İskenderun Baseni) bağlayan kenet, Misis, Andırın ve Engizek hattı boyunca uzanmaktadır. Bu alanın batısında yer alan Misis yükseliminin uzantısı bugün deniz seviyesi altında devam eden bir sirt boyunca Kuzey Kıbrıs'taki Girne dağ silsilesine bağlanmaktadır (Şekil 1).

İnceleme alanınında yüzeyleme veren en önemli ünite Misis-Andırın kompleksidir. Misis-Andırın kompleksinin Misis segmenti, nispeten daha istikrarlı ve kolay anlaşılır özellikte olan 2 üniteye ayrılmaktadır. Bunlardan birincisi yapısal olarak altta yer alan Geç Kretase-Erken Tersiyer yaşlı volkano-sedimanter ünite ve ikinci olarak da yapısal olarak bunları üzerleyen melanj birimidir.

Misis-Andırın Kompleksi, yapısal olarak orta derecede kuzeye eğimli bir bindirme ile Miyosen yaşlı havza çökellerini üzerlemektedir. Bölgedeki bazı TPAO kuyu verilerinin de bu Miyosen türbiditlerinin varlığını doğruladı $\breve{g} 1$ gözlenebilmektedir. Daha güneydeki bazı diğer kuyularda ise bu geç Miyosen türbiditleri tarafından üzerlenmiş olan Erken Miyosen yaşlı türbiditler kesilmiştir. Misis segmenti kuzey kenarında ise genellikle Pliyo-Kuvaterner yaşlı karasal sedimanlarca üzerlenmektedir (Şekil 2).

Misis-Andırın kompleksi'nin önemli bir bölümünün yüzeylediği Misis Yapısal Yükselim alanı, Adana ilinin yaklaşı $30 \quad \mathrm{~km}$ doğu/güneydoğusunda yer alan çalışma bölgesini kapsamakta olup, Adana Baseni ile İskenderun basenlerini birbirinden ayırmaktadır. Bu yükselim tektonik etkenlere bağlı olarak geliştiğinden yapısal bir yükselim olduğu kabul edilmektedir. $\mathrm{Bu}$ yükselim bölgesinin sinırları hem kuzey hem güneyden kalın bir alüvyon örtüsü ile örtülü bulunduğundan bu sinırların özelliklerini belirlemek ve tektono-startigrafik ilișkileri tam olarak ortaya koymak çözülmesi gereken önemli bir jeolojik problemi oluşturmaktadır [1].

Misis Yapısal Yükselimi Adana'nın Ceyhan ilçesi ile buraya yakın konumda bulunan Yakapınar (Misis) mahallesi ile Güveloğlu mahallesi arasında kalan bölge boyunca yaklaşık KD-GB doğrultulu bir uzanıma sahiptir (Şekil 1). Güney kesimlerinde Yumurtalık körfezi ve sahil kumulları bulunmaktadır. Kuzeyinde ise Neojen Adana 
Havzasına ait kalın bir sedimanter örtü ile sınırlandırılmıştır. Bu düz alan içerisinde Misis Yapısal Yükselimi Geniş bir alanda göze çarpan en önemli topoğrafik yükselim alanı olarak göze çarpmaktadır. $\mathrm{Bu}$ çalışmanın amacı yukarıda bahsedilen karmaşık tektonik ortam içerisindeki ünitelerin tektono-stratigrafik ilişkilerini daha detaylı olarak ortaya koyarak bölgenin jeodinamik geçmişi hakkında daha fazla bilgi sağlamaktır.

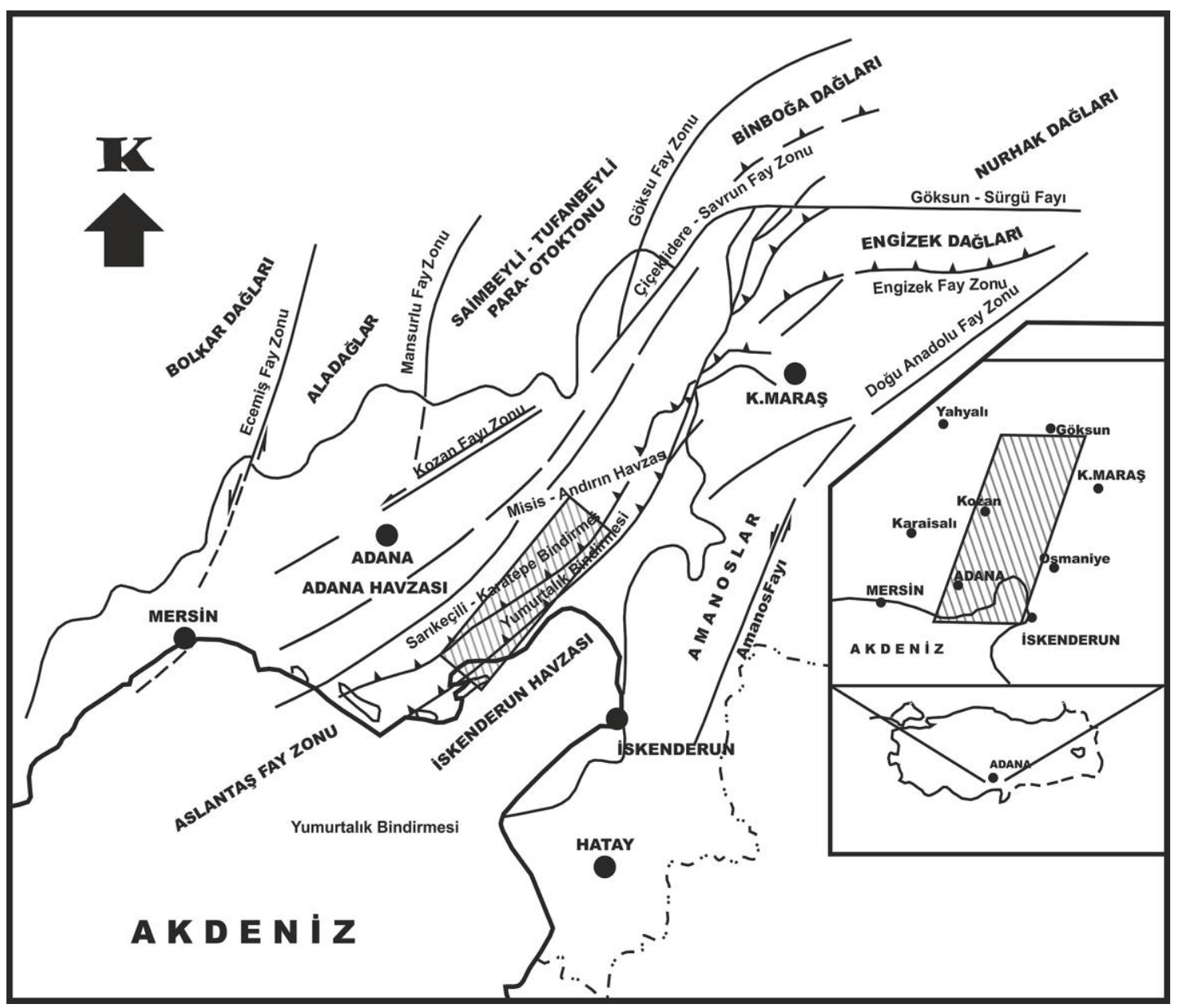

Şekil 1. Çalışma alanının Doğu Akdeniz bölgesi içindeki konumunu ve ana tektonik hatlar ile olan ilişkisini gösteren yapısal harita (Kozlu [3]'den değiştirilerek)

\section{GENEL BİLGILER}

Türkiye tektonik açıdan yer küredeki en aktif kıtasal bölgelerinden biri üzerinde yer almaktadır. Kuzeye doğru hareket eden Afrika-Arap levhaları ve göreceli olarak durağan olan Avrasya levhası arasında kalan Anadolu levhacı̆̆ı sıkışma tektoniğinin etkisi altında sağ yanal doğrultu atımlı Kuzey Anadolu Fay Zonu (KAFZ) ve sol yanal doğrultu atımlı Doğu Anadolu Fay Zonu (DAFZ) olarak isimlendirilen iki büyük fay zonu boyunca batıya doğru hareket halindedir [313]. DAFZ kuzeydoğuda Karlıova'dan başlayarak güneybatıda Anadolu-Arap-Afrika üçlü ekleminin şekillendiği Türkoğlu (Kahramanmaraş) bölgesinde Ölü Deniz Fayı ile birleşmektedir [14, 15]. DAFZ Türkoğlu civarında batı ve güneybatıya doğru çatallanarak uzanım göstermektedir. 
Güneybatıya doğru Amanos Fayı üzerinden Amik ovasına doğru uzanarak bu bölgede Hatay’ın Kuzey kesiminde Afro-Arap levhaları ile Anadolu levhacığı arasında üçlü birleşme alanını oluşturmaktadır [16]. DAFZ'ın batıya doğru uzantısı ise Osmaniye üzerinden Ceyhan ve çalışma alanını da kapsayan alan üzerinden Akdeniz'in içerisinden Kıbrıs'a kadar uzanmaktadır (Şekil 1). Bu ana fay sistemlerinin yanı sıra bölgede farklı doğrultularda irili ufaklı birçok fay yer almaktadır.

Afrika levhasını çevreleyen okyanus ortası sırtlarının ıraksayan levha sınırlarındaki hareket ve Kızıldeniz'deki açılma nedeniyle, Arap Levhası, Afrika levhası ile beraber Ölü Deniz Fay Zonu boyunca kuzeye doğru kayarak Afrika-Arabistan ve Avrasya levhalarının kuzey-güney doğrultuda yakınsamalarına ve birbirlerini sıkıştırmalarına neden olmaktadır. Bunun sonucu olarak Arabistan levhası, Bitlis-Zagros Kenet Kuşağı (BZKK) veya Güneydoğu Anadolu Bindirmesi boyunca Avrasya levhasının altına dalarak çarpışmışlardır [17]. Günümüzde de devam eden bu sıkışma sonucunda Güneydoğu Anadolu Bölgesi ve kuzey kesiminde kuzey-güney yönlü sıkışmanın özelliğini gösteren bir fay sistemi gelişmiştir.

$\mathrm{Bu}$ fay sistemi içinde bindirme fayları, makaslama fayları, normal faylar ve büyük açılma çatlakları gelişmiştir. Bölgeyi etkileyen bu fayların en büyükleri sol yönlü Doğu Anadolu Fay Zonu ve Bitlis Zagros Kenet Kuşağı adı verilen bindirme karakterli faylardır (Şekil 1). Lice Fay Zonu, Adıyaman Fay Zonu, Bozova ve Kalecik fayları gibi Bölgedeki bütün kırık hatları bu sisteme bağlı olarak gelişmiş faylardır. Doğu-batı gidişli faylar tamamen ters fay veya bindirme karakterli faylardır. Kuzey-güney gidişli faylar da normal eğim atımlı faylar veya açılma çatlakları (gerilme çatlakları) şeklinde gözlenmektedir [18].

Güneydoğu Anadolu bölgesi Torid ve Arap platformunun çarpışmasına bağlı olarak oluşmuş olan kenet bölgesindeki üniteler farklı araştırmacılar tarafından belirli bölümlere ayrılarak incelenmiştir. Rigo de Righi and Cortesini [19] Güneydoğu Anadolu Bölgesini stratigrafik özellikleri bakımından değerlendirmek üzere Toros Orojenik Kuşağı, Kenar Kıvrımları Kuşağı, Kıvrımlanmış Kuşak ve Ön Ülke olmak üzere 4 ana kuşağa ayırarak incelenmektedir.

Güney Tetis okyanusunun Kretase sonlarında kıta kenarlarına yerleşmiş olan kalıntıları Türkiye'nin güneyi üzerinden Bitlis-Zagros hattı boyunca İran’a doğru uzanmaktadır. Bu okyanusal kabuğun Geç Kretase-Erken Tersiyer zamanı boyunca kuzey yönlü yitim, doğrultu atımlı tektonik ve çarpışmalı tektonik rejimlerin neticesinde aşamalı olarak kapandığ 1 görüşü jeologlar tarafından geniş bir kabul görmüştür.

Doğu Toros Otokton kayaçları ile ilişkisi görülmeyen ve Adana Baseni ile Amanoslar arasında kalan Misis-Andırın Yapısal Yükselimi içerisinde yer alan çalışma alanında (Şekil 1) genellikle Tersiyer yaşlı birimler gözlenmektedir.

$\mathrm{Bu}$ bölgede stratigrafik konum olarak alttan üste doğru; Alt Eosen yaşlı İsalı Katastrofik Fasiyesi (Dokuztekne Volkano-sedimanterleri); Üst Kretase-Alt Miyosen yaşlı Andırın Formasyonu, Andırın Formasyonu'nun üyeleri olan Üst Kretase yaşlı Dokuztekne üyesi ve Üst Eosen-Oligosen yaşlı Bulgurkaya Olistostromu; Alt Miyosen yaşlı Gebenköy Formasyonu; Alt-Orta Miyosen yaşlı Karataş Formasyonu; Üst Miyosen yaşlı Kızıldere Formasyonu; Üst Pliyosen-Alt Pleistosen yaşlı Delihalil Bazaltı; Üst Pliyosen-Kuvaterner yaşlı kaliçi-taraça ve Kuvaterner yaşlı alüvyonlar yer almaktadır (Şekil 3).

Misis-Andırın havzası KD-GB uzanımı boyunca iki dilimden meydana gelmiştir [20]. Birinci dilim, Misis-Andırın bölgesinde bloklu karışı̆̆ı oluşturan ve blokların yer aldığı Bulgurkaya Olistostromunun yer aldığı çökel havzasıdır. Bu havza üzerine Akitaniyen-Burdigaliyen yaşlı Gebenköy Formasyonu ilksel ilişkili olarak gelmekte ve birimin tavanına doğru ve KB devaminda Adana Baseninin Miyosen istiflerine geçilmektedir. İkinci dilim havzanın GD kanadında olup, Alt-Orta Miyosen yaşlı Aslantaş ve Karataş Formasyonlarının çökelme alanıdır. 


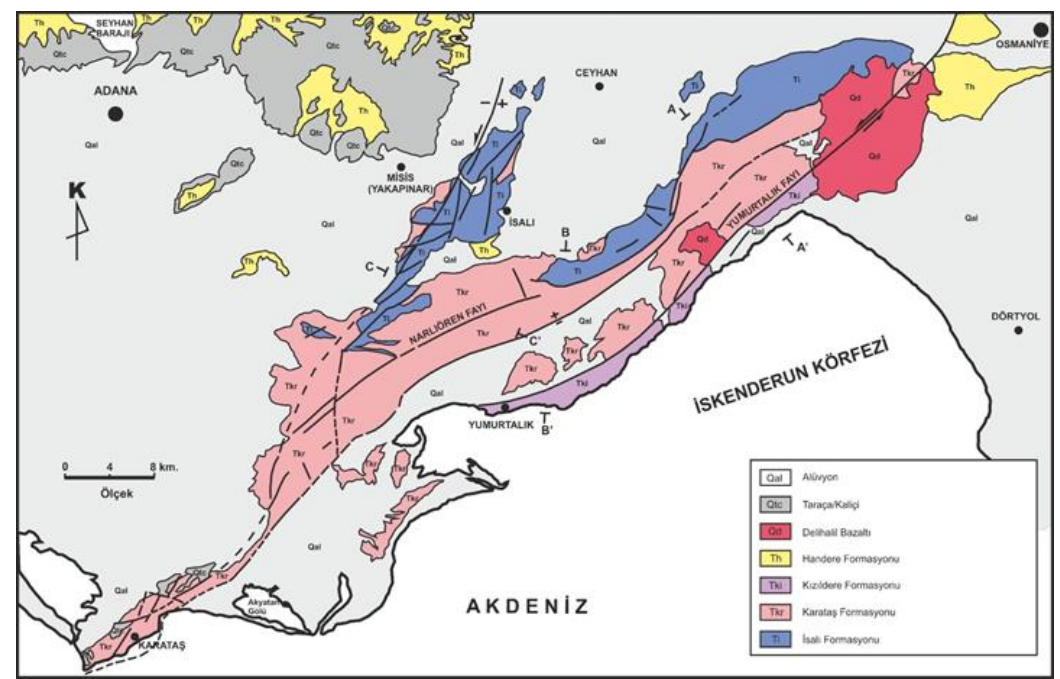

Şekil 2. Doğu Akdeniz bölgesinde inceleme alnını da içeren geniş bir alanın jeolojik haritası (Ünlügenç [2]'den değiştirilerek)

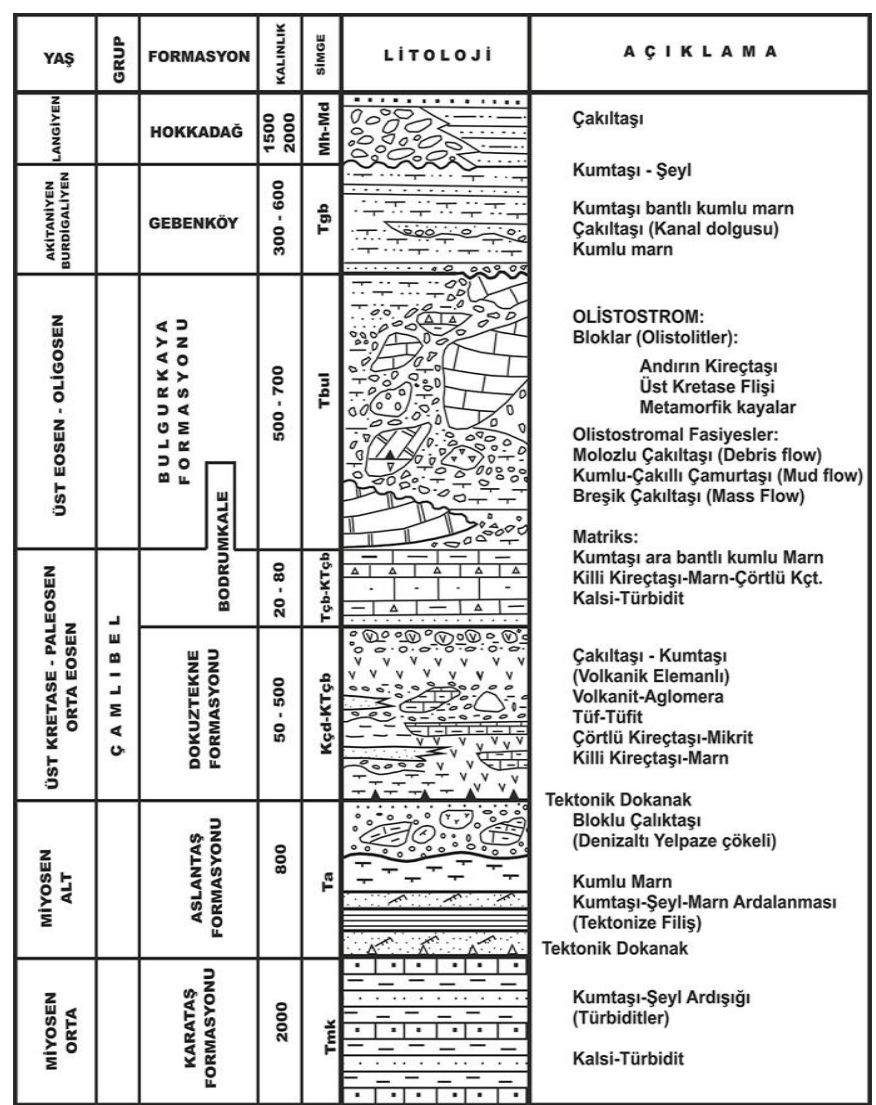

Şekil 3. Çalışma alanı çevresindeki birimlerin stratigrafik ilişkisini gösteren ölçeksiz stratigrafik sütun kesit [20] 


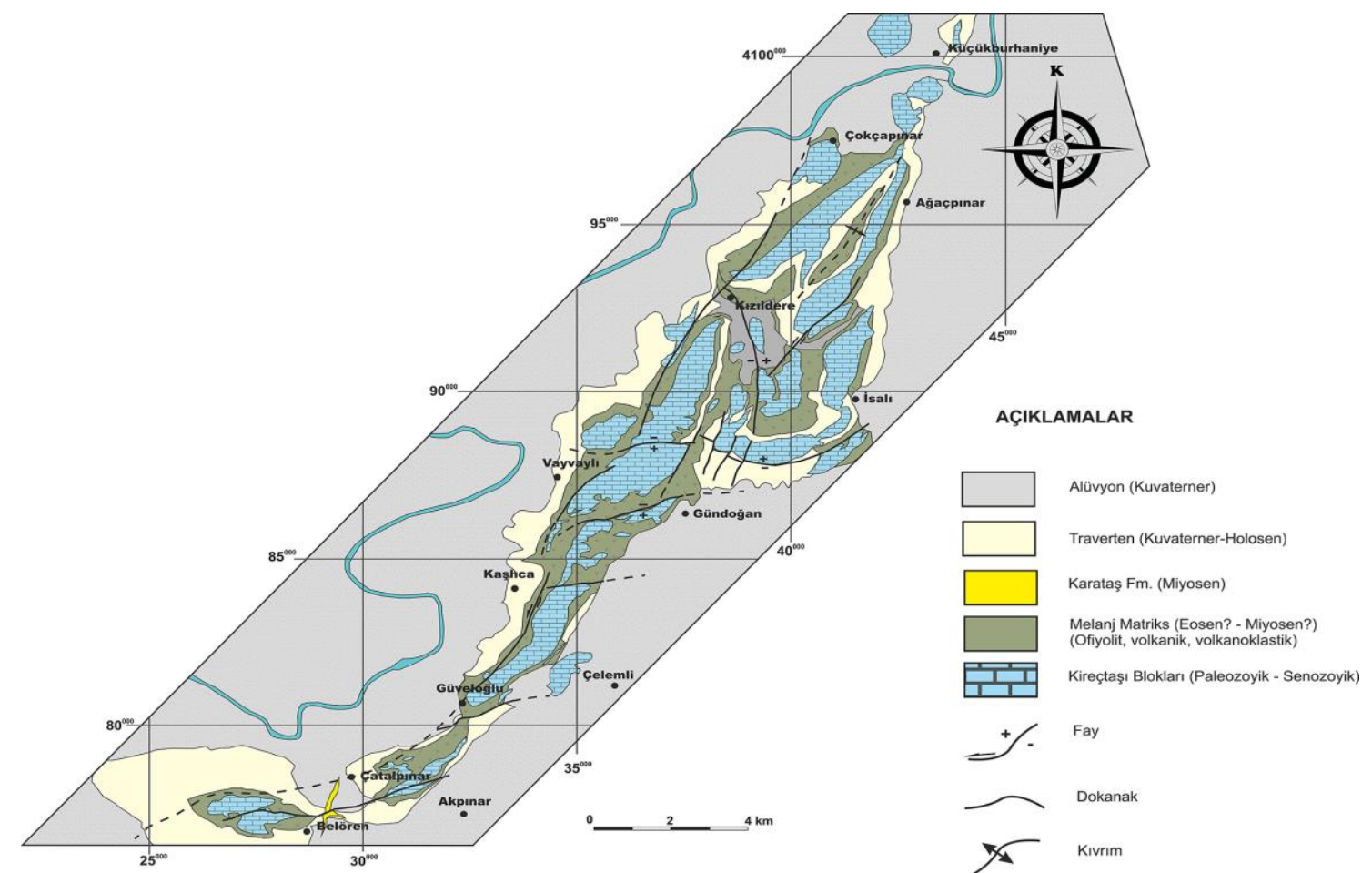

Şekil 4. Çalışma kapsamında hazırlanan inceleme sahasının jeolojik haritası (1/25.000 ölçekten küçültülerek)

\section{TEKTONO-STRATIGRAFI}

İnceleme alanında yüzeyleme veren en önemli ünite olan Misis-Andırın birliği; güneyde Karataş, batıda Adana-Yakapınar (Misis), doğuda Ceyhan ile Yumurtalık arasında uzanan bölgeyi içerisine almaktadır (Şekil 1, 2).

Doğu Toros otokton kayaları ile ilişkisi görülemeyen ve Adana havzası ile Amanoslar arasında kalan Misis grubu, Dokuztekne, Andırın ve Karataş Formasyonlarına ayrılarak (Şekil 3) incelenmiştir.

\subsection{Dokuztekne Formasyonu (KTçd)}

Bölgede, bu birim volkano-sedimanter bir istifle temsil edilir. Altta manganezli kireçtaşı düzeyleri bulunduran, tüflerle başlayan birim, üste doğru spilitik aglomera, volkanik elemanlı kumtaşları ve killi kireçtaşı ara seviyeli aglomeralarla devam eder.
Kalınlığı 1500 - $2000 \mathrm{~m}$ arasında değişen bu birimin alt dokanağı tektonik olup, üstüne ise uyumsuzlukla Andırın Formasyonu gelir [20]. Formasyonun yaşı Maestrihtiyen-Alt Eosen'dir.

Birim, Misis-Ceyhan bölgesinde (Şekil 4); Tutlupınar, Dokuztekne, Sarıkeçili, Kurtkulağı, Narlı köyleri çevresinde, Doruk belediyesi güney kesimlerinde ve Aslantaş bölgesindeki Çamlıbel köyleri dolayında geniş yayılım gösterir [20].

Dokuztekne Formasyonu, Misis yapısal yükseliminin bulunduğu hat boyunca genellikle Mesozoyik yaşı kireçtaşı blokları ve ofiyolitik kayaç toplulukları ile beraber karışmış ekaylı kütleler şeklinde izlenmektedir. Kozlu [20], Schmidt [22]'nin bu birimi "İsalı Katastrofik Fasiyesi" olarak adlandırdığını belirtmiş olup, 1987'deki çalışmasında bu birimi Dokuztekne volkano-sedimanter birimi adı altında Çamlıbel Grubuna dahil ederek incelemiştir. Oysaki 
Schmidt'in İsalı Katastrofik Fasiyesi olarak adlandırdığı birim daha çok Misis-Andırın Karmaşı̆̆ına (Melanj) karşılık geldiği düşünülmektedir.

\subsection{Bulgurkaya Olistostromu (Tbul) (Misis- Andırın Melanjı)}

$\mathrm{Bu}$ çalışmada Bulgurkaya Sedimanter Melanjı olarak tanitılacak olan birim, ilk kez Schmidt [22] tarafindan İsalı Katastrofik Fasiyesi içinde tanımlanmıştır. Daha sonra Erdoğan [23] tarafından birim Göksun/Helete civarındaki Geç Eosen yaşlı alacalı kırıntılılar için Alacık Formasyonu adı ile tanımlanmıştır. Bilgin ve arkadaşları [24] ise birimi Andırın Formasyonu içinde tanımlamıştır. Birim daha sonra Perinçek ve Kozlu [25] tarafindan Demiroluk Fm. olarak adlandırılmıştır. Kozlu [19], çalışmasında Andırın ilçesinin batısındaki Bulgurkaya köyündeki olistostrom fasiyeslerinin tip yüzeylemelerinin görüldüğü yere atfen 1997 yılında sunduğu doktora tezinde [20] birimin kaotik yapısını düşünerek formasyon adı kullanmak yerine olistostrom terimini kullanmıştır.

Çoğunlukla serpantinitlerden oluşmuş moloz akması özelliğindeki Andırın Formasyonu (melanjı) içinde, çakıldan çok büyük olistolitlere kadar değişik boyutta olasılı Paleozoyik yaşlı rekristalize kireçtaşı, Mesozoyik ve Eosen yaşlı kireçtaşları, volkanik ve ofiyolit blokları yer alır (Şekil 5, 7).

Formasyonun, yakın çevreden, çeşitli sedimanter ve ofiyolitik kayaların aşınarak dar ve uzun bir havzada hızlı depolanması ile oluştuğu düşünülmektedir. Açısal uyumsuzlukla Dokuztekne Formasyonu üzerine gelen bu birim, üstte Karataş Formasyonu tarafindan açısal uyumsuzlukla örtülür. Birimin yaşı Üst LütesiyenAlt Miyosen'dir.

Melanj içinde en çok göze çarpan kaya birimi, aşınmaya karşı olan dayanımından dolayı kireçtaşlarıdır. Özellikle Mesozoyik yaşlı kireçtaşları ve dolomitik kireçtaşları oldukça sert yapıda olduğundan yükselim içerisindeki en yüksek alanları oluşturmaktadır. Dikkatli incelendiğinde boyutları yüzlerce metreye varabilen bu kireçtaşı bloklarının kendi içlerinde yoğun bir deformasyonun izlerini taşıdığını görmek mümkündür. Özellikle yüksek açılı kıvrımlı yapılar ve faylanmaların izleri blokların içinde yer yer korunmuştur.

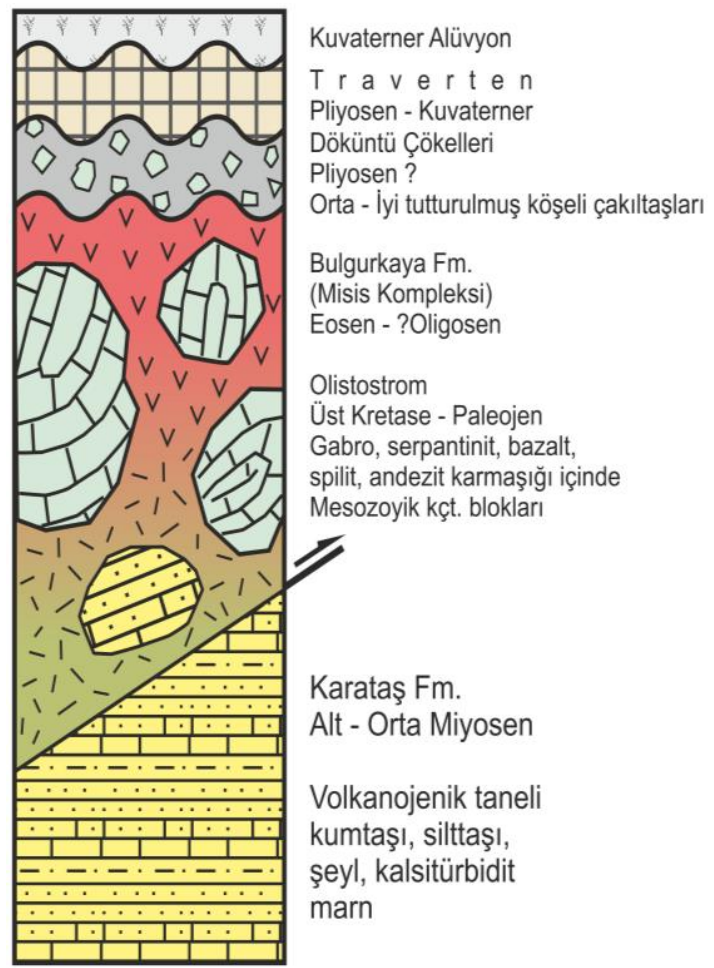

Şekil 5. İnceleme alanında gözlenen birimlerin tektono-stratigrafik sütun kesiti

Birimin matriksini oluşturan ünite ise genellikle serpantinit, gabro gibi ofiyolitik kayaçlar ile bazalt, spilit, andezit gibi volkanik kayaçlardan, volkanoklastik kumtaşlarından ve türbiditik kırıntılılardan ibarettir (Şekil 7, 8). Bu birimler ayrışmaya karş1 duraysız birimler olduğundan yüksek ölçüde topraklaşmışlardır ve korunmuş taze yüzey veren mostraları ancak genç vadiler ile yeni açılmış yol yarmalarında görülebilmektedir. Özellikle İnceleme alanının Güney kesimlerindeki Güveloğlu mahallesi civarında açılmış olan yeni yol yarmalarında serpantinitleri gözlemlemek mümkündür. $\mathrm{Bu}$ bölgede üzerinde $\mathrm{K} 1 \mathrm{z}$ Kalesi adı da verilen tarihi bir kalenin de inşa edilmiş olduğu dev bir kireçtaşı bloğu ile olan ilişkisini izlemek mümkündür. 


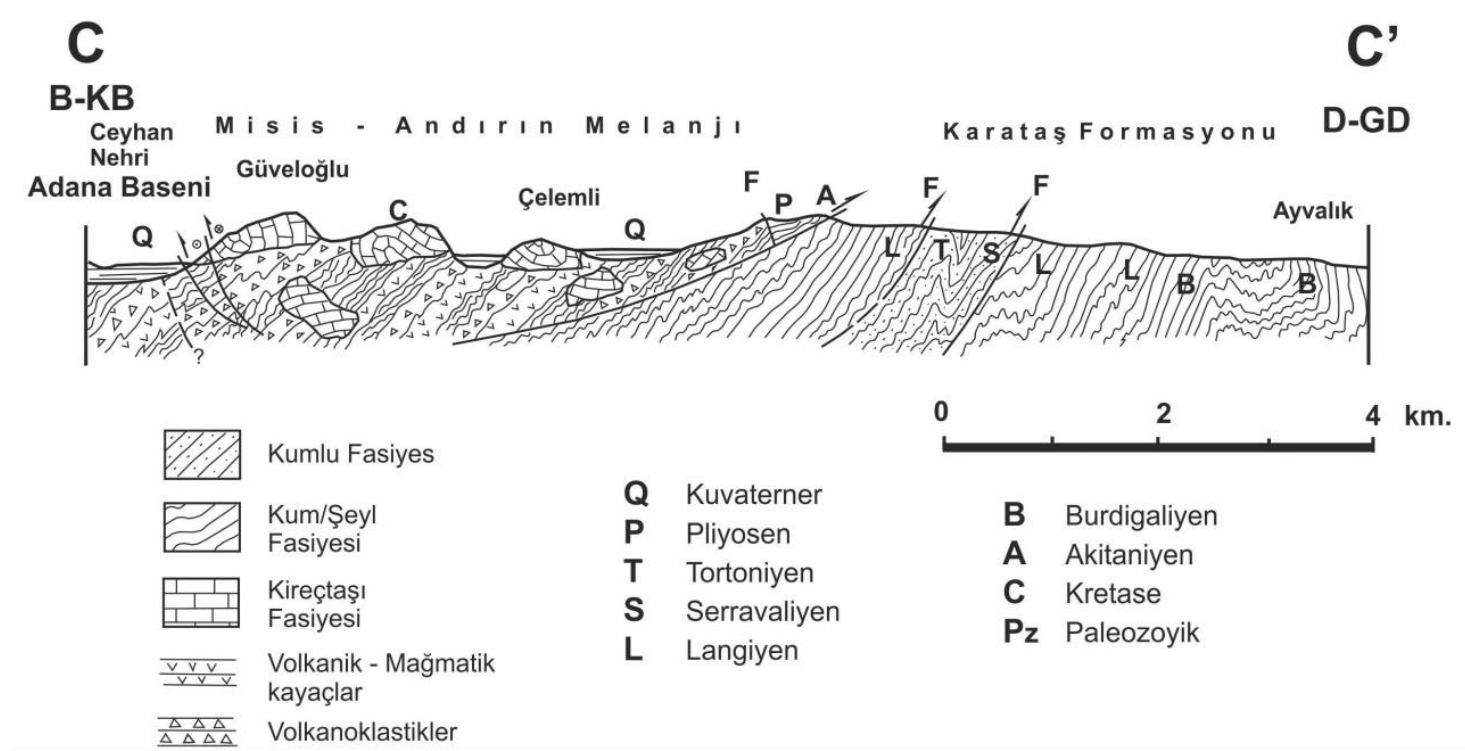

Şekil 6. Çalışma alanından BKB-D-GD yönlü olarak alınmış ölçekli jeolojik enine kesit (Kelling ve arkadaşları [28]'den değiştirilerek)

$\mathrm{Bu}$ yöredeki ofiyolitik kayaçların bünyesinde deformasyonların izlerini görmek de mümkündür. Arazi çalışmalarında birim içerisinde gözlemlenmiş olan bu deformasyon yapılarındaki düzlemsel ve çizgisel veriler ölçülmüştür. Bunların önemli bir bölümünün orta ve yüksek açılı ve doğrultu atımlı bileşeni de olan faylar olduğu görülmektedir. Melanj içinde özellikle bünyesindeki sert yapıdaki kireçtaşı gibi kaya blokları ile olan dokanaklarına yakın kesimlerde ezilme zonlarının bulunduğu ve deformasyonun daha ileri seviyelere ulaştı̆g 1 da gözlenmiştir.

Misis uzanımı boyunca Bulgurkaya olistostrumu, Jura'dan Oligosen'e kadar değişen yaş aralıklarında yüzlerce metre boyutlara varabilen breşleşmiş kireçtaşı blokları ile temsil edilmektedir $[25,26]$. Blokların önemli bir bölümü hemen hemen eş boyutludur ve breşleşme sonucu örtülmemiş olan kısımlarında ilksel stratigrafisini korumaktadır. Önceki bazı çalışmalarda büyük bloklar olarak haritalanmış olan bazı kireçtaşı mostraları arjilik (killi) kızılımsı siltli (fosilsiz) nadiren mostra veren bir matriks içinde köşeli küçük kireçtaşı bloklarından oluşmaktadır. Daha büyük boyutlu blokları oluşturan kireçtaşları genellikle yeniden kristalize olmuştur [1]. Bununla birlikte yer yer kavkı parçaları, ekinodermler, bentik foraminiferler (miliolid) ve algli kireçtaşları da gözlenmektedir. Az rekristalize olmuş olan kireçtaş1 ince kesitleri mikrobiyal karbonat, kavk1 parçaları, iri foraminiferler (Nummulit, Miliolid), detrital kuvars, kuvarsit, detrital kumtaşı, mermer, nadir silisik lav (kuvars mikrofenokristalli) ve biyotit içerir [1]. Yer yer ornatma kökenli çörtler (genellikle breşleşmiş) görülmektedir. Ayrıca seyrek mermer blokları ikincil mikaşist içermektedir.

Birimin matriksi sadece yersel olarak iyi bir şekilde mostra vermektedir. Buralar genellikle yol yarmaları veya taş ocaklarıdır. Melanjın taban kesimlerine yakın yerlerde ekaylı kumtaşları mikrospar matriks içinde yarı küresel mikritik karbonat taneleri, bazalt, kırmızı radyolaryalı çört ve seyrek kuvars, mikrobiyal karbonat ve onkolit içermektedir. Melanjın üst seviyelerinde matriks Ceyhan'ın $18 \mathrm{~km}$ doğusunda bulunan Dutlupınar köyü $\left(37^{\circ} 01^{\prime} 69^{\prime}, \mathrm{K}-36^{\circ} 01^{\prime} 02^{\prime}\right.$ 'D) civarında iyi mostra vermekte ve kırmızımsı yeşilimsi renkli masif veya belirsiz tabakalı matriks destekli konglomeralar 5 metre'den az kalınlıkta çökeller 
oluşturmaktadır [1]. İnce taneli matriks sedimanları yer yer silisleşmiştir. Farklı moloz çökelleri hem monomiktik hem polimiktik karakter sunmaktadır. Bazı seviyelerde (15 m kalınlığa varan) göreceli olarak daha iyi tabakalanmış türbiditik havza dışı kayaç parçaları içeren kumtaşları ve çamurtaşları görülmektedir.

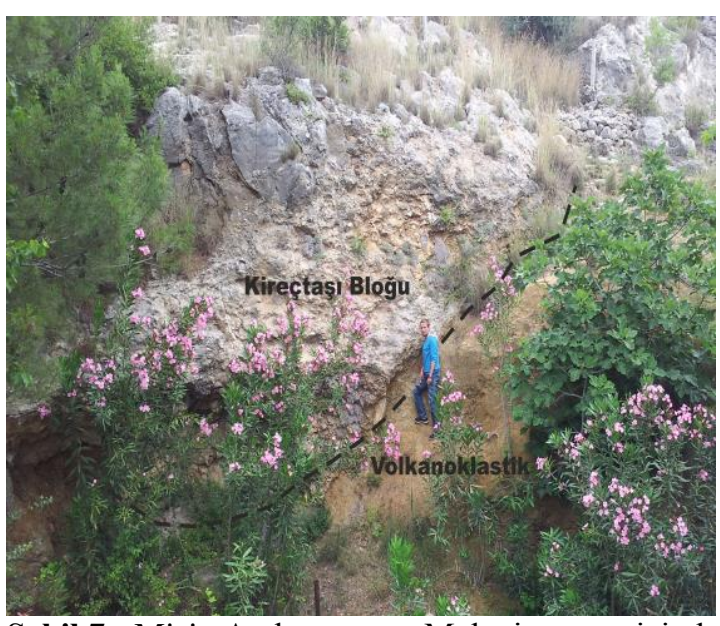

Şekil 7. Misis-Andrın Melanjı içinde volkanoklastik malzeme ve bünyesindeki dev kireçtaşı bloğunun arazi görünümü

Moloz çökelleri içindeki taneler genellikle litolojik olarak daha büyük ayrılmış bloklara benzer olan karbonatlı kayaçlardan oluşur. Ayrıca gelişigüzel yönlenmiş, genellikle yarı küresel-yarı köşeli ofiyolit kökenli kayaçlar (bazalt, diyabaz, gabro, serpantinit), iyi çimentolanmış volkano-klastik kumtaşları (nadir), kırmızı şeritli radyolarit ve pembe renkli pelajik (kristalize olmayan) kireçtaşları yaygındır [1]. Ayrıca gabro, serpantinit, plajiyoklas, ortoklaz, mikroklin, pertitik feldspat, piroksen, radyolaryalı çört, ekinoderm parçaları, radyolaryalı mikrit, planktik foraminifer, kavkı parçaları ve kalkarenit gözlenir. Nadir görülen değişik derecelenmiş kalkerli kumtaşları türbiditik karakterdedir. Bunlar genellikle yeniden çökeltilmiş pelajik karbonatlardan, az miktarda altere bazalt, metamorfik kuvars, mikaşist, biyotit, plajiyoklas, polikristalin (metamorfik) kuvars, kuvars, kırmızı radyolaryalı çört, piritik şist, milonit, mikrobiyal karbonat, kavkı parçaları ve detritik kuvarsit türü kumtaşlarından oluşmaktadır [27].
Matriks içindeki çökellerde gözlenen mikrofosiller taşınmış olduğundan yaşlandırmak oldukça zordur. Gökçen ve arkadaşları [27] tabakalı matriks içinde planktonik foraminifer olan Globogerinoides primordius tespit etmişlerdir. Buna ek olarak Globoquadrina dehiscens egzotik bloklar içinde belirlenen en genç türdür. Her ikisi de yaş olarak Erken Miyosen olduğundan Gökçen ve arkadaşları [28] melanj için en erken Miyosen yani Akitaniyen yaşını vermişlerdir. Ayrıca, Gökçen ve arkadaşları [1] ve Kozlu [20] tarafindan Eosen-Oligosen yaşl1 çeşitli planktonik foraminiferler belirlenmiştir. Bu mikrofosil sonuçlarının önemi mikrofosillerin melanj içindeki tabakalı istiflerde mi yoksa erozyon-yeniden çökelme veya diapirik ortam içinde daha derinlerden mi taşındığına bağlıdır. Sonuç olarak Melanjın yaşı bir bütün olarak, güneydeki levha üzerindeki en genç korunmuş istiften alınan Erken Eosen yaşına ve yersel olarak mostra veren Melanjın üzerindeki örtüden alınan Erken Miyosen yaşına dayanmaktadır [1].

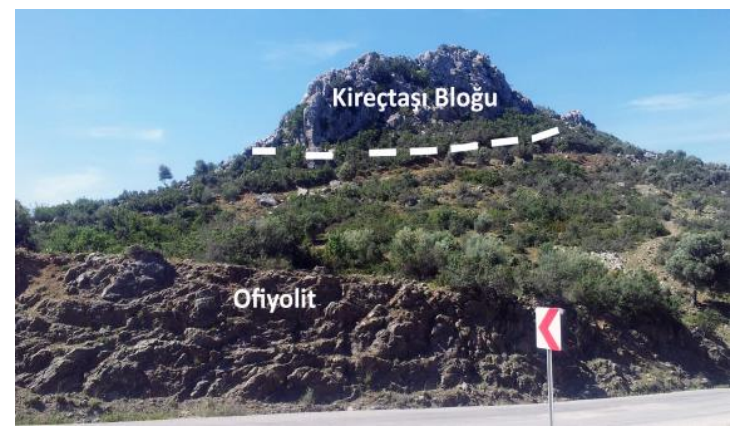

Şekil 8. Misis-Andrın Melanjı içinde ofiyolit ve içindeki kireçtaşı bloğunun arazi görünümü

Bulgurkaya olistostromu bünyesinde bindirme, yersel kıvrımlanma ve doğrultu atım tektoniğinin izleri gözlenmektedir [3,29] Matriks büyük ayrılmış bloklarla olan sınırlarına yakın yerlerde genellikle ekaylanmıştır. Makaslama zonları ve mostra ölçeğinde kıvrımlar matriksi etkilemiştir. Buna ek olarak kireçtaşı blokları genellikle yoğun bir şekilde breşleşmiş olup, Ceyhan'ın $12 \mathrm{~km}$ doğu-güneydoğusunda Adana-Osmaniye otobanının kuzeyindeki ocaklarda (3700'33.68''K-35'58'44.65' 'D; Dokuztekne kuzeyinde) iyi mostralar vermektedir [1]. Parçalar 
tipik olarak birkaç cm. boyuta ulaşabilmekte ve genellikle köşeli olup, ufalanmış karbonat taneleri dışında matriks içermemektedir. Yersel olarak yaygın yapboz dokusu gözlenmektedir, öyle ki taneler birbirine yersel olarak önceki sedimanter dokusunu ortaya koyabilecek şekilde yerleşmiştir. Parçalanma blokların kenar kesimlerinde arjilik (killi) matriksin görüldüğü yerlerde en fazladır. Çok benzer özellikteki breşler Kuzey Kıbrıs’taki Girne uzanımında gözlenen Mesozoyik yaşlı neritik kireçtaşlarında da belirlenmiştir [29]. Bu tektonik breşler melanjın oluşumu için öne sürülen gravitasyonal kuvvetlerin egemen olduğu tektonik rejim ile açıklanabilecek parçalanmaya yol açan gerilmeli strese bağlanmıştır [1].

Misis segmenti bir bütün olarak mostra ölçeğinde genellikle iyi gelişmiş fay çizikleri içeren çok sayıdaki makaslama düzlemleri ile deforme olmuştur. Karakteristik fay düzlemleri (doğu kesimlerde Adana-Osmaniye otobanı civarında) yaklaşık olarak KD/GB gidişli olan komplekse dik (normal) olarak gelişmiştir. Fay düzlemlerinin üzerindeki fay çizikleri sol yanal doğrultu atımın daha ön planda olduğuna işaret etmektedir. Buna ek olarak karmaşık kilometrelerce uzanan aşınmış dik şevlerle kendini belli eden KD-GB gidişli yüksek açılı faylar tarafından kesilmiştir (Dutlupınar köyü güneybatısı). Kuzeydoğuda (Nurdağı) karmaşı direk olarak genç ekstansiyonel veya transtansiyonel fay sarplığına yaslanmaktadır. Komşu Ceyhan alüvyal düzlüğü 1998'de sol yanal doğrultu atım aktivitesine bağlı büyük bir depreme maruz kalmıştır [27].

\subsection{Karataş Formasyonu (Tka)}

Karataş Formasyonu adını Schmidt [22] tarafından Karataş ilçesinden alınarak verilmiştir. Karataş Formasyonu genelde kumtaş1-marn-kumlu kireçtaşı-çamurtaşı ardalanması ile temsil edilen türbiditik bir istiftir (Şekil 9). Çoğun olitostromal düzeylerde yaygın olmak üzere, çeşitli yaşta ve litolojide bloklar içerir. Ayrıca sedimantasyon sırasında naplar ve bloklar şeklinde havzaya taşınmış olan Andırın Formasyonuna ait kayaları da bulundurur. Andırın Formasyonu üzerine uyumsuzlukla gelen birim, genç çökeller tarafından uyumsuzlukla örtülür. $2500 \mathrm{~m}$ veya daha fazla kalınlığa sahip Karataş Formasyonu içindeki değişik seviyelerden alınan örneklerdeki fosiller Alt-Üst Miyosen yaşını vermiştir [30].

Misis yapısal yükseliminin bulunduğu bölge içerisinde bu birimin yayılım alanı Sarıkeçili ile Çuhadarlı bindirmeleri ile GB'dan ve güneyden Yumurtalık fayı ile sinırlandırılır. Bu bölgede genel özellikleri itibarı ile türbiditik bir özellik taşımaktadır. Birim genellikle kumtaşı ve şeyllerden oluşmaktadır. Birimin egemen litoloji ise kumtaşıdır (Şekil 9). Kumtaşlarının taze kırık yüzey rengi grimsi, kahverengimsi, altere yüzeyleri ise koyu kahve, yeşilimsi renkli, orta-iyi gelişmiş paralel tabakalanmalı ve yer yer derecelenmelidir. Birim iyi çimentolanmış olduğundan sertliği özellikle ince taneli kesimlerde yüksektir. İnce taneli şeyl tabakaları ise grimsi, boz renkli, ince-orta tabakalı ve göreceli olarak daha yumuşak ve yer yer dağılgandır.

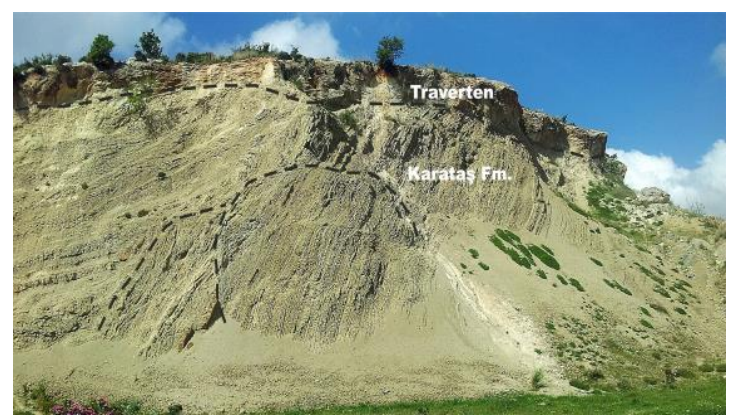

Şekil 9. Karataş Formasyonu ve üzerine uyumsuz gelen Traverten ünitesinin görünümü

Formasyonun alt sınırını bölgede büyük kırık ve fay hatları nedeni ile görmek mümkün olmamıştır. Formasyonun alt sınırı bir ters fay ile kırılarak Kızıldere Formasyonu ile tektonik dokanak ilişkisi göstermektedir, yalnız Kurtkulağı köyünün güney kesiminde Dokuztekne Formasyonu üzerinde yersel bir yüzeyleme verdiği belirtilmektedir [31]. Birimin üst dokanağı ise genellikle tektoniktir. Misis-Andırın meanjı veya Bulgurkaya Olistostromu olarak tanıtılan birim birçok yerde bu birim üzerine bindirmeli olarak gelmektedir. Bu ilişki bölgede ancak yükselim alanının kenar kesimlerinde özellikle genç molozlar veya kaliçileşmiş birimler ile örtülü olmadığı nadir yerlerde izlemek mümkün olabilmektedir. 
Birim için Eroskay [32], çalışmalarında Miyosen içinde herhangi bir ayrım yapmamış ve geniş olarak Miyosen yaşını verdikleri Kuzgun Formasyonunu tanımlamışlardır. $\mathrm{Bu}$ birim genellikle Adana Baseni içindeki kumtaşı, çakıltaşı litolojileri olarak değerlendirilmekte olup, Boyraz (2002) [31] ise inceleme alanına yakın yerdeki Karataş Formasyonu ile özdeş kabul edilebileceğini belirtmiştir.

\subsection{Kızıldere Formasyonu (Tki)}

Birim adını Schmidt (1961)'in [22] ilk kez kullandığı ve bölgedeki yerleşim yerlerinden Kızıldere Köyüne atfen Kızıldere Formasyonu olarak almıştır. İnceleme alanında kısıtlı bir yayılıma sahiptir. Geniş yayılımını daha güney kesimlerde göstermektedir.

Formasyon en altta, konglomera ve resifal kireçtaşları ile başlar. Üste doğru kalın katmanlı kumtaşı ve marnlara geçiş yapar (Şekil 10). Marnlar koyu gri renktedir. Seyrek olarak görülen killi kireçtaşları, açık krem renkli, kırılgan, laminalı ve bol killidir. Ara seviyelerde yer yer bazaltlar türü volkanikler gözlenmektedir. Alttaki birimler üzerine uyumsuz olarak gelen birimin üst dokanağı Yumurtalık fayı boyunca türbiditik Karataş Formasyonu ile faylıdır. Formasyonun üst sınırı belirsiz olmakla beraber yaklaşık $1500 \mathrm{~m}$ kalınlık sunar. Birimin yaşı Üst Miyosen olarak verilir [30].

Kizıldere Formasyonunun regresif bir karakter sunması nedeni ile bazı yerlerde konglomera, bazı yerlerde resifal kireçtaşı, bazı yerlerde ise istifin üst ardalanma seviyeleri tabanda yer alabilmektedir [31]. Birimin tabanına yakın kesimlerde görülen taban konglomeraları Formasyonun altındaki birime ait çakılları yer yer bünyesine almıştır. Tabandaki bazı konglomeraların kızılımsı renkte olduğu görülmektedir. $\mathrm{Bu}$ konglomeraları oluşturan çakıllar genellikle mağmatik kayaçlar ve dolomitik kireçtaşlarıdır.

Konglomeraların bu kızılımsı rengi içerdiği kireç ve bol demirli çimentodan gelmektedir. Kızıldere Formasyonunun tabanında yer yer görülen resifal nitelikteki kireçtaşları, alg, tekçe ve koloni halinde mercan ve Gastropod gibi makrofosillerdir [31].

Birimin daha üst seviyelerinde ise kumtaşı, marn ve killi kireçtaşları gibi seviyeler görülebilmektedir. Kumtaşları, ayrışma yüzeyi koyu grimsi, boz renkli, taze kırık yüzeyi ise gri renkli, az dayanımlı, yer yer gevşek çimentoludur. Tane boyu inceden kabaya değişmekle birlikte dayanımsız olması sebebi ile el örneğinden ince kesit hazırlanırken parçalanmaktadır.

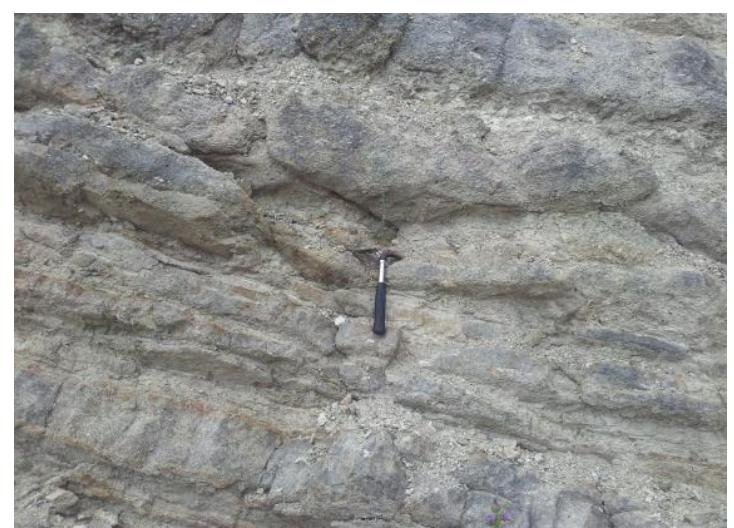

Şekil 10. Kızıldere Formasyonuna ait kırıntılı ve karbonatlı kayaçların mostra görünümü

Çakıl taşlarında, çakılların genellikle yuvarlaklaşmış olduğu az köşeli olduğu görülmektedir. Çakılların büyüklüğü $25-30 \mathrm{~cm}$ boyutlarına ulaşabilmektedir. Marnlar ise grimsi veya koyu grimsi renkleriyle dikkat çekmektedirler. Daha az kil içeren killi kireçtaşları ise daha açık renklerde krem renginde veya boz renkli olup kırılgan yapıdadır. Bu seviyelerde yer yer düzensiz laminalanma görülebilir. Yer yer içerdiği kil miktarı artmaktadır. Killi kireçtaşları ile marnların ardalanmalı olarak görüldüğü yerlerde yersel olarak somatr ortam ürünü bitki kalıntıları gözlenmiştir. Bazı seviyelerde ise Bazaltlara rastlanmıştır [31].

Kizildere Formasyonunun taban seviyelerinde transgresif özellikler görülmektedir [31]. Formasyonun çökelimi kızılımsı renkli çakıltaşları ile başlamaktadır. Bu litoloji genellikle sığ denizel ortama işaret etmekte olup, içerdiği malzemeyi üzerine çökelmiş olduğu ofiyolitik kayaçlardan 
almaktadır. Konglomeraların üzerine resifal kireçtaşları gelmektedir. Daha üst seviyelerde ise silttaş1-kumtaşı ardalanması ve marn-kumtaşı ve çakıllı kumtaşı birimlerinin ardalanımları gelmektedir. $\mathrm{Bu}$ seviyelerdeki kalın kumtaşı tabakaları ve marn ardalanımları ortamın sı ğ olmakla beraber bölgeye taşınan malzemenin periyodik olarak değişebildiğini göstermektedir [31].

Kozlu [19], birimin yaşını SerravaliyenMessiniyen, Gültekin ve arkadaşları [33] ise Tortoniyen-Messiniyen olarak vermiştir. Eroksay ve arkadaşları'nın [32] Kuzgun Formasyonu ile Gözübol ve Gürpınar'ın [34] Kuzgun Formasyonu kapsamındaki Üst Miyosen yaş aralığına giren çökelleri Kızıldere Formasyonu ile korele edilebilecek özelliktedir [31].

\subsection{Delihalil Bazaltı}

Yumurtalık, Ceyhan, Osmaniye ve Haruniye yörelerinde yüzlekleri bulunan Kuvaterner yaşlı bazaltlar Delihalil Formasyonu bölgedeki Delihalil tepeye atıf edilmek üzere Kozlu [35] tarafindan adlandırılmıştır. Çalışma alanında büyük bir yayılım sunmamakla beraber bölgesel olarak önemli bir yayılıma sahiptir. Bölgedeki Bazaltik volkanizma çok değişik örnekler sunmaktadır. Delihalil tepe ve Üç tepe konilerinde tutturulmamış piroklastikler; volkan bombası, lapilli, süngertaşı gibi elemanlardan oluşmaktadır. Lav akıntılarının altında sarı-pembe renkli gevşek dokulu tüfler bulunmaktadır. Üstteki lav akıntıları ise çok dayanımlıdır ve akıntı izleri taşımaktadır. Delihalil bazaltları bölgedeki en genç oluşumları kesen faylar boyunca ve yakın civarlarında mostralar sunduğundan oluşum yaşı Kuvaterner olarak düşünülmektedir. Önceki çalışmalarda Schmidt [22] birimin yaşını Pleistosen, Schiettecatte [36] ise Holosen olarak vermișlerdir.

Genellikle genç tektonik hatlar boyunca yarık erüpsiyonu şeklinde çıkan bu volkanitler, siyah renkli, gözenekli, gaz boşluklu ve kırmızımsı- gri ve siyah renkli tüflerin ardalanımı şeklinde gözlenebilmektedir [31]. Sıkışma tektoniğinin etkili olduğu inceleme alanında KD-GB yönelimli ikincil kırık-yarık hatlarının oluşturduğu zayıflık zonlarından bu bazaltik özellikteki malzeme yer yüzeyine akmış ve yüzeye gelirken de muhtemelen mevcut birimlerden bünyelerine katmış oldukları malzemeler ile birlikte yer yer de kirlenerek yüzeylemiş olan birimler üzerinde soğumuşlardır [37].

\subsection{Kaliçi ve Traverten $(Q k)$}

Kaliçi oluşumu traverten oluşumu ile benzerlik gösterir. Kurak mevsimlerde $\mathrm{CaCO}_{3}$ taşıyan suların yer yüzüne çıkmaları sürecinde kayacın bünyesinde buharlaşması sonucunda taşıdıkları kireçli maddeleri çökeltmeleri ile oluşmuşlardır. $\mathrm{Bu}$ birimler Misis tepeleri bölgesinde yamaç eğimine uygun konumda geniş alanlarda çökelmişlerdir. Kalınlığı birkaç santimetreden birkaç metreye ulaşmaktadır. Yaşı KuvaternerHolosen'dir [30].

Traverten çökelimleri inceleme alanında özellikle yükselim alanının KB-GD cephesinde olmak üzere geniş bir yayılıma sahiptir. Bu bölgelerde Misis-Andırın melanjı ile altındaki birimlerin tektonik ilişkisini de birçok bölgede örterek gizlemektedir. Birimler topoğrafya ile tamamen uyumlu bir konumda bulunmaktadır. Ayrışmış yüzey renkleri boz, grimsi bir renge sahip olup, taze yüzeyleri ise hafif kirli beyaz renktedir. Yüzeye yakın kısımlar oldukça sertleşmişken, daha alt seviyeleri daha yumuşak yapıdadır. Birimin kalınlığının Misis yükseliminin bulunduğu alanda en fazla 6-7 metreye ulaştığı gözlenmiştir. Yer yer bünyesinde Mesozoyik yaşlı kireçtaşı çakıllarını da kapsamaktadır. Alınan bazı kalker örneklerinde bol miktarda sı ̆ denizel ortamı karakterize eden fosiller içerdiği de gözlenmiştir.

\subsection{Alüvyon (Qal)}

Adana havzasında, Adana ovasını oluşturan eski alüvyonlar ile dere boylarında gelişmiş genç alüvyonlar bulunmaktadır. Eski alüvyon genellikle bitkisel toprak ile örtülü bulunmaktadır. Yeni alüvyonlar ise dere boylarında gelişmiş olup, genelde kötü boylanmalı, tutturulmamış çakıl, kum ve milli malzemeden oluşmuştur. 
Misis Yapısal Yükselim alanında ise yer yer moloz akması ürünü malzemeler görülmektedir. Bunlar, bölgedeki yoğun tektonik aktiviteyi işaret eder niteliktedir. Bazı yerlerde bu birimler az miktarda çimentolanma göstermektedirler. Yer yer özellikle zayıf tutturulmuş olduğu yerlerde traverten ile üzeri örtülmüş bir konumda bulundukları dikkat çekmektedir. Faylar tarafından aşındırılmış dik vadi yamaçlarında ise tutturulmamış köşeli çakıl yığınları şeklinde geniş alanlar kapladıkları gözlenmektedir.

\section{SONUÇLAR}

Anadolu, Afrika ve Arap levhalarının üçlü birleşme noktasına (triple junction) oldukça yakın konumda bulunan ve bu levhalar arasındaki jeodinamik hareketlerin etkisi ile şekillenmiş olan inceleme alanındaki tektono-stratigrafi özellikle Misis Yapısal Yükseliminin gelişim süreci ile yakından ilişkilidir. $\mathrm{Bu}$ yapı aynı zamanda bölgenin depremselliği ve jeolojik geçmişi açısından önemli bir tektonik uzanım konumundadır.

Gerçekleştirilen detaylı jeolojik saha çalışmaları sonucunda Adana ilinin güneydoğu kesiminde yer alan çalışma sahası Kızıldere-Güveloğlu (Yakapınar) bölgesinde Eosen-Oligosen yaşlı Bulgurkaya Formasyonu'nun tektonik dokanak ile Alt-Orta Miyosen yaşlı Karataş Formasyonunu üzerlediği gözlenmektedir. $\mathrm{Bu}$ birim üzerine diskordans ile Pliyosen (?) yaşlı yamaç molozu çökelleri gelmektedir. Bu çökellerin üzerinde ise yine düşük dereceli açısal bir uyumsuzluk ile ile yataya yakın bir konumda olmak üzere PliyoKuvaterner yaşlı traverten ve kaliçi çökelleri gelmektedir. Tüm bu birimler yükselim alanının kuzey ve güney kesiminden Kuvaterner yaşl1 alüvyon örtü ile uyumsuz olarak örtülmektedir.

\section{TEŞEKKÜR}

Bu çalışma Ç.Ü. B.A.P. Birimi tarafından (Proje No: MMF2013BAP16) desteklenmiştir.

\section{KAYNAKLAR}

1. Robertson, A.H.F., Ünlügenç, U.C., İnan, N., Tasl, K., 2004. The Misis-Andirin Complex: a Mid-Tertiary Melange Related to Late-stage Subduction of the Southern Neotethys in $\mathrm{S}$ Turkey. J. Asian Earth Sci. 22, 413-453.

2. Ünlügenç, U.C., 1993. Controls on Cenozoic sedimentation in the Adana Basin, Southern Turkey. Unpublished Ph.D Thesis, Keele University, UK, p. 229.

3. Kozlu, H., 1987. Misis-Andırın Dolaylarının Stratigrafisi ve Yapısal Evrimi, Türkiye Petrol Kongresi Dergisi 7:104-116.

4. Ketin, İ., 1948. Über die Tektonischmechanischen Folgerungen aus den Grossen Anatolischen Erdbeben des Letzten Dezenniums. Geol. Rundsch. Pp. 36,77-83.

5. McKenzie, D.P., 1972. Active Tectonics of the Mediterranean Region. Geophysical Journal of the Royal Astronomical Society 30, 109-185.

6. Dewey, J.F., 1976. Ophiolite Obduction: Tectonophysics, v. 31, p. 93-120.

7. Şengör, A.M.C., 1979. The North Anatolian Transform Fault: its Age, Offset and Tectonic Significance, Jour. Soc. London, 136, 269-282.

8. Şengör, A.M.C., Canitez, N., 1982. The North Anatolian Fault. Berchemer and K. Hsü (eds.), Alpine and Mediterranean Geodynamics de. Geodynamical Series, American Geophysical Union, 7, 205-216

9. Hempton, M.R., Savc1, G., 1982. Elazığ Volkanik Karmaşığının Petrolojik ve Yapısal Özellikleri: Türkiye Jeol. Kur. Bült., 25, 143-150.

10. Şengör, A.M.C., Görür, N., Şaroğlu, F., 1985. Strike-slip Deformation Basin Formation and Sedimentation. Society of Economic Palaeontologists and Mineralogists Special Publication 37, 227-264.

11. Barka, A.A., Kadinsky-Cade, K., 1988. Strikeslip Fault Geometry in Turkey and it's Influence on Earthquake Activity, Tectonics, 7 (3), 663-684.

12. Barka, A. A., Reilinger, R.E., 1997. Active Tectonics of the Eastern Mediterranean Region Deduced from GPS, Neotectonic and 
Seismicity Data. Annale de Geofisica. XL, 587-610.

13. Çetin, H., Güneyli, H., Mayer, L., 2003. Paleoseismology of the Palu-Lake Hazar Segment of the East Anatolian Fault Zone, Turkey. Tectonophysics, 374, 163-197.

14. Karig, D.E., Kozlu, H., 1990. Late Palaeogene Evolution of the Triple Junction Region Near Maras, south-central Turkey. Journal of the Geological Society, London 147, 1023-1034.

15. Perinçek, D., Çemen, İ., 1990. The Structural Relationship Between the East Anatolian and Dead Sea Fault Zones in Southeastern Turkey, Tectonophysics 172, 331-340.

16. Över, S., Ünlügenç, U.C., 1998. Seismotectonic Evidence of the Antioch Triple Junction and Resent Temporal Change in Qaternary to Present-day Stress State Along Hatay Region (SE-Turkey), Third International Geology Symposium, Ankara.

17. Şengör, A.M.C., 1980. Türkiye'nin Neotektoniğinin Esasları: Türkiye Jeol. Kur. Yayl., Ankara.

18. Yilmaz, Y., 1993. New Evidence and Model on the Evolution of the Southeast Anatolian Orogen. Geological Society of America, Bulletin 105, 251-271.

19. Rigo de Righi, M., Cortesini, A., 1964. Gravity Tectonics in Foothills Structure Belt of SE Turkey. American Association of Petroleum Geologists Bulletin 48, 1911-1937.

20. Kozlu, H., 1997. Doğu Akdeniz Bölgesinde Yer Alan Neojen Basenlerinin (İskenderun, Misis-Adırın) Tektono-stratigrafi Birimleri ve Bunların Tektonik Gelişimi. Doktora Tezi.

21. Dim, Y., 2010. Misis Yapısal Yükseliminde (GD Adana) Yer Alan Türbiditlerdeki Tabaka Kalınlık ve İç Yapı Değişimlerinin İstatistiksel Analizi, Çukurova Üniversitesi, Fen Bilimleri Enstitüsü, Adana, Yüksek Lisans Tezi, $92 \mathrm{s.}$

22. Schmidt, G.C., 1961. Stratigraphic Nomenclature for the Adana Region Petroleum District VII. Petroleum Administration Bull. Ankara 6:47 63.

23. Erdoğan, T., 1975. Gölbaşı Yöresinin Jeolojisi (Geology of the Gölbaşı Region). Turkish Petroleum Company Field Group Report, Ankara, 229.
24. Bilgin, A. Z., Elibol, E., Bilgin, Z. R., Beğenilmiş, S., 1981. Ceyhan-Karataş Yumurtalık - Osmaniye - Haruniye - Kadirli Dolayının Jeolojik Raporu General Directorate of Mineral Research and Exploration, Rept.7215 (unpublished).

25. Perinçek, D., Kozlu, H., 1984. Stratigraphy and Structural Relations of the Units in the AfşinElbistan-Doğanşehir Region (Eastern Taurus), Proceedings of International Symposium, Geology of Taurus Belt, MTA, Ankara-Turkey, 181-198.

26. Gökçen, S.L., Kelling, G., Gökçen, N., Floyd, P.A., 1988. Sedimentology of a Late Cenozoic Collisional Sequence: the Misis Complex, Adana, Southern Turkey. Sedimentary Geology 59, 205-235.

27. Gökçen, N., Gökçen, S.L., Kelling, G., 1991. Microfaunal Biostratigraphy of Cenozoic Sequences from the Misis-Andirın area, Southern Turkey. (C) Gebruder Bornisraeger. D.100 Berlin, D-7000 Stuttgart, 111-135.

28. Kelling, G., Gökçen, S.L., Floyd, P.A., Gökçen, N., 1987. Neogene Tectonics and Plate Convergence in the Eastern Mediterranean: New Data from Southern Turkey. Geology 15, 425-429.

29. Robertson, A.H.F., Woodcock, N.H., 1986. The Geological Evolution of the Kyrenia Range: a Critical Lineament in the Eastern Mediterranean. Philosophical Transactions of the Royal Society, London A317, 141-171.

30. M.T.A. Adana İli Jeolojik Özellikleri, http://www.mta.gov.tr/v2.0/bolgeler/adana/bol gesel-jeoloji/jeoloji-adana.pdf.

31. Boyraz, O., 2002. Demirtaş-Sarımazı (Adana Yumurtalı) Arasının Tektonostratigrafisi, Jeoloji Mühendisliği Anabilim Dalı, Adana, Yüksek Lisans Tezi, $46 \mathrm{~s}$.

32. Eroskay, O., Yılmaz, Y., Gürpınar, O., Yalçın, N., Gözübol, A.M., 1978. Ceyhan Berke Rezervuarının Jeolojisi ve Mühendislik Özellikleri: Türkiye Jeoloji Kurumu Bülteni, 21, 51-66.

33. Gültekin C., Yeniay, G., Kozlu, H., 1992. İskenderun Baseninde Horu Formasyonunun Stratigrafisi ve Çökelme Ortamı: Türkiye 9. Petrol Kongresi ve Sergisi, Ankara Türkiye s. 142-150. 
34. Gözübol, A. M., Gürpınar, O., 1980. Kahramanmaraş Kuzeyinin Jeolojisi ve Tektonik Evrimi. Türkiye 5. Petrol Kongresi Jeoloji-Jeofizik Bildirileri, 21-29, Ankara.

35. Kozlu, H., 1982. İskenderun Baseni Jeolojisi ve Petrol Olanakları. TPAO Rapor no: 1921, Ankara.

36. Schiettecatte, J.P., 1971. Geology of the Misis Mountains. In: Campbell, M., (Ed.), Geology and History of Turkey, Tripoli, Libya, Petroleum Exploration Society, pp. 305-312.

37. Bilgin, A. Z., Ercan, T., 1981. CeyhanOsmaniye Yöresindeki Kuvaterner Bazaltların Petrolojisi. TJK Bülteni, 24, 21-30. 
